\title{
Information and Communication Technologies Usage in Working with Families of Early Aged and Preschool Children with Visual Impairments in Terms of Distance Psychological and Pedagogical Support
}

\author{
Tatiana Kostenko ${ }^{1 *}$, and Kateryna Dovhopola ${ }^{1}$ \\ ${ }^{1}$ Department of Education of Visually Impaired Children, Institute of Special Pedagogy and \\ Psychology named after Mykola Yarmachenko, National Academy of Pedagogical Sciences of \\ Ukraine, 9, M. Berlinskoho St., Kyiv, 04060, Ukraine Kyiv, Ukraine
}

\begin{abstract}
This paper presents the results of studying the use of information and communication technologies (ICT) in working with families of early aged and preschool children with visual impairments. The authors analyze the current situation in families during strict quarantine in 2020 and 2021 and study the possibilities of using information technology in the development of children with visual impairments at home. The study describes how or under what circumstances specialists worked with families of early aged and preschool children with visual impairments, what problems parents, professionals faced, and whether they were ready to solve - via the author's questionnaires for professionals and parents, identified current problems that need urgent solutions. The theoretical basis and practical side of studying the problem of using information and communication technologies in families' distance psychological and pedagogical support are presented. Attention is focused on different levels, and specialists with children with visual impairments in the context of family education and the absence or insufficiency of distance correction work with early aged children and their parents are emphasized. The need for further study of the situation for the development of appropriate forms, methods of ICT in working with families of children of early and preschool age with visual impairments. The relevance of scientific research on the use of ICT and distance psychological and pedagogical support is proved, as this format will be in demand not only during lockdown but also in seasonal outbreaks, challenging weather conditions, as well as constantly for families living in settlements, remote from International Rescue Committee and other educational institutions, families who due to various life circumstances are not able to visit institutions that provide educational and psychological services. It is concluded that there is an urgent need to create a holistic system using ICT to work with families of early aged and preschool children with visual impairments, which will help solve a wide range of psychological and pedagogical rehabilitation support tasks. Keywords:
\end{abstract}

\footnotetext{
* Corresponding author: tanya t.k@ukr.net
} 
information and communication technologies, children with visual impairments, early age, preschool age, distance learning, surveys.

\section{Introduction}

The modern period of educational development is characterized by the increasing role of information and knowledge, which become factors of social progress and well-being. The development of the information society causes changes in almost all spheres of life. The availability of information and communication technologies (ICT) dramatically changes the way we work with data, simplifies the processes of knowledge acquisition, exchange of experience and interaction between people.

Ukrainian society is currently experiencing severe challenges related to the periodic imposition of quarantine in the country caused by the effects of the COVID-19 pandemic. In such crises, professionals working with children with visual impairments show an increase in problems of various kinds due to the low level of information and communication technology during the period of remote provision of counselling, correctional and diagnostic services. Psychological support for families of children with visual impairments is usually provided in the absence of ICT support and low correctional and diagnostic capabilities. These facts lead us to say that issues related to providing psychological assistance to families of visually impaired children who are in solitary confinement can no longer remain within the scope of providing individual assistance to parents or children. There is an urgent need to develop a remote psychological and pedagogical support system for families with children with special educational needs in modern Ukraine, subject to a prior detailed study of the issue.

Formulation of the problem. The lack of a systematic approach to creating opportunities for ICT use in working with families of young and preschool children with visual impairments has become a serious obstacle to effective care for these families. In conditions of self-isolation due to a pandemic, children with visual impairments do not receive proper exceptional and psychological and pedagogical support, which negatively affects their development, inhibiting the success of habilitation, rehabilitation and inclusion.

Currently, scientists from the Mykola Yarmachenko Institute of Special Pedagogy and Psychology of the National Academy of Pedagogical Sciences of Ukraine have developed distance learning models for people with special educational needs in quarantine, which allow them to work at home with the whole class under the guidance of a teacher-mastering the methods of learning. Many measures are taken to train specialists in providing psychological assistance to families raising children with special needs: special seminars and supervision groups are held for psychologists, social educators and representatives of other related professions; methodical materials of informative and educational character are developed and distributed (mainly through social networks), etc. However, an essential condition in working with visually impaired children in correctional and developmental work should begin as early as possible. However, today not only there is little research on the education, upbringing and socialization of children with visual impairments of early and preschool age, but also no work and experience on the use of ICT in remote support for children in this category and their parents [1], [2].

Therefore, the issue of development and implementation of scientific research, which will determine the organizational and methodological conditions for using ICT in working with families of visually impaired children of early and preschool age, is acute.

ICT in working with families of visually impaired children of early and preschool age in the remote form of psychological and pedagogical support is an innovative form of support based on both the best traditional methods of support and new information and interactive 
technologies. At the same time, this form is not available to all population segments and depends on many factors, including material security, place of residence and health status [3].

\section{Analysis of recent research and publications}

A number of domestic and foreign studies have focused on addressing the introduction of ICT in the educational process of children with special needs, taking into account their educational needs, in particular in the works of B. Eckert, G. Hoppe, H. Lobin, V. Bykov, V. Zasenko, B. Moroz, V. Ovsyanyk, L. Prokhorenko, O. Rybalko, O. Romanenko, B. Shunevych and others. [4], [10].

Researchers worked on the development and application of practical forms and methods of working with children with visual impairments: V. Bochelyuk, O. Bezpal'ko, I. Hryha, E. Daniels, N. Zhyhaylo, I. Zvyeryeva, I. Ivanova, A. Kaps'ka, A. Kolupayeva, H. Laktionova, M. Lukashevych, I. Myhovych, T. Semyhina, P. Talanchuk, S. Tolstoukhova, A. Turubarova, L. Tyuptya, M. Firsov, O. Kholostova, M. Chaykovs'kyy, Ye. Yars'kaSmyrnova and other scientists.

Problems of life of children with visual impairments are considered in research H. Hryhor'yevoyi, M. Zemtsova, N. Kyyanytsi, Z. Kruchynina, K. Lebedyns'koyi, V. Myasyshcheva, L. Hovikovoyi, Ye. Syn'ovoyi, L. Solntsevoyi, V. Feoktystovoyi, I. Kholkovs'koyi, V. Shnayder, D. Uorrena. Along with these studies, there are several works on the effects of visual deprivation (V. Andriyenko, L. Vavina, L. Vyhot·s'kyy, V. Zhurov, V. Kobyl'chenko, L. Kunenko, O. Lytvak, I. Morhulis, L. Nafikova, V. Remazhevs'ka, T. Svyrydyuk, Ye. Syn'ova, Ye. Sternina, A. Suslavichus, V. Feoktystova etc.). The authors argue that in conditions of visual deprivation disrupts the processing and perception of the information content of cognitive material by children, so the organization of the educational process requires special additional equipment and informatization [6], [7].

Currently, the informatization of the education system relies on a set of theoretical and methodological provisions in the education of children with special needs: the use of information technology in special and inclusive education is found in the works V. Zasenko, B. Moroz, V. Ovsyanyk etc.; research of possibilities of increase of efficiency of training of such children with the use of electronic game resources in elementary school - V. Bikov, S. Litvinova, O. Melnik; study of the peculiarities of the classification of objects of the information field by children with mental retardation - L. Prokhorenko, O. Romanenko [2], [8], [11].

However, despite differing views on this issue, researchers agree that using information and communication technologies will contribute to the acquisition of skills to apply knowledge in a variety of, sometimes extraordinary, situations, enriching the practical experience of a child with special educational needs.

A child with visual impairments has the opportunity to learn about the world around them only with the help of preserved analyzers. Therefore, many researchers believe that the mental development of such children, the formation of compensatory processes, active life position, awareness and mastery of ways of self-realization depends on various conditions biological, social, psychological, and incredibly educational (T. Dehtyarenko, K. Dovhopola, Ye. Klopota, V. Kobyl'chenko, O. Lehkyy, Ye. Syn'ova). Scientists claim that the use of information technology in the education of children with visual impairments creates favourable conditions for their education in all educational institutions, regardless of ownership, access to educational services, active participation in society and others.

Unresolved aspects of the problem. Despite numerous scientific studies, the use of ICT in working with families of young and preschool children with visual impairments remains open and underdeveloped. According to scientists, the success of the education of children 
with visual impairments depends on the educational environment in which the child is, on the correctional and developmental orientation of the content of education, which should include the development of compensation, correction and restoration of impaired functions, search for potential opportunities for development and knowledge children with visual impairments. In this context, the very use of ICT allows children to learn according to their characteristics and capabilities, even remotely.

The purpose of the article is to outline the results of studying the use of ICT in working with families of young and preschool children with visual impairments in the context of remote psychological and pedagogical support.

\section{Theoretical fundamentals of research}

The analysis of theoretical research shows that the issue of using ICT in working with families of young and preschool children with visual impairments became acute when educational institutions were forced to switch to distance learning. During this period, the organization of the educational process for children and the continuation of counselling, correctional and developmental work with children with visual impairments at home was threatened. Given that ensuring access to education for children with visual impairments requires the use of special devices, which are one way to compensate for visual deprivation, a channel of communication with the environment, a conductor of information, the question of studying ICT in working with families of children with visual impairments early and preschool age [8], [9].

In our opinion, the development and application of flexible strategies and techniques, using modern information and communication technologies that would take into account the individual characteristics of families with young and preschool children with visual impairments, will address the above issues of further remote psychological and pedagogical support.

It should be noted that ICTs act as a powerful means by which specialists in different situations can always accompany a child with visual impairments. The use of information technology promotes the development of children's visual impairment of thinking, memory, ability to self-organization and co-creation, increases learning motivation, and hence the level of their socialization [5], [9].

Scientists conclude that information technology has a positive effect on the process of learning and education primarily because they change the scheme of knowledge transfer and teaching methods [2], [5]. At the same time, the introduction of such technologies in the education system of children with visual impairments is based on the use of special equipment, software and hardware, information processing systems, unique teaching methods and more. There is very little research on ICT use for children of this nosology of early and preschool age, which requires complex and active intervention from scientists.

\section{Research methodology}

The experimental work was carried out in three stages. In the first stage, questionnaires with open-ended and closed-ended questions were developed for professionals working with visually impaired children and for parents, grandparents, guardians or other persons directly involved in the care, development and upbringing of visually impaired children from birth to the age of 7-8 years at home.

The purpose of the survey was to find out the current situation in the families and communities of professionals during the severe quarantine in 2020 and 2021, the possibilities 
of using information technology in the development of children with visual impairments, to identify current problems that need urgent solution.

The second stage involved the distribution of questionnaires on social networks, data collection. At the third stage, all the obtained data were processed and processed, including Fisher's angular transformation that had been used.

\section{Research results}

One hundred fifty-seven answers were received to the questionnaire for specialists, including $56.7 \%$ of teachers, $30.6 \%$ of correctional teachers, $9.6 \%$ of psychologists, $3.2 \%$ of specialists said they combine several functions, 3.2\% - chose the answer " Your option. " It should be noted that none of the specialists chose the item "early intervention specialist", which, in our opinion, is a confirmation of the fact of acute shortage of such specialists in Ukraine.

Among the respondents, $17.2 \%$ work with young children and $82.8 \%$ with preschool children. At the same time, $11.5 \%$ of all specialists deal with children of both early and preschool age.

Of all respondents, $84.1 \%$ during the lockdown in 2020 worked with children with visual impairments in the online format using ICT, respectively, $15.9 \%$ did not. This indicates that most professionals quickly (not to say that comfortable and/or practical) moved to a new work format. In our opinion, this is because the education of children with special educational needs in Ukraine is currently under development and reform. Most professionals are constantly looking for new technologies and work methods, attend various training events and are open to new things, so they are potentially ready to react quickly to change.

However, it should be noted that only $51.6 \%$ of respondents conducted online classes (of various formats) with all their students (clients), while $48.4 \%$ of professionals had families with whom there were no relevant classes. The reasons for this difference can be different, for example, the unwillingness of families to work in a new format for them, lack of technical capabilities and others.

To the question "What format of work did you use?" we received the following answers (note that one respondent could choose several answer points if he used different forms): $74.5 \%$ conducted online consultations for parents (or persons caring for the care, upbringing and development of children with visual impairments); $50.3 \%$ conducted online classes directly with children; only $10.8 \%$ disassembled home video and provided relevant advice on its results; $73.2 \%$ sent tasks that parents performed independently at home with their children; $70.1 \%$ provided telephone consultations. Separately, we note that $4.5 \%$ of respondents did not use the remote format, and $12.1 \%$ chose the item "other". Note that the last two indicators are close to $15.9 \%$ of professionals who did not work with children with visual impairments online. At the same time, under the item "Other", there may be such options as "met on the street during a walk", "gave home visits", "took the child home for private lessons", or others.

Among the respondents, $89.8 \%$ provided assistance (of various formats, not only with the use of ICT) to families and children during the severe quarantine and lockdown in 2020. Only $10.2 \%$ did not work with their families at that time.

When asked whether the situation with the use of ICT has changed during the lockdown in early $2021,56.7 \%$ answered in the affirmative and $43.3 \%$ - in the negative.

The following answers were received to the question of what was the biggest obstacle and challenge in the organization of work with the use of ICT (respondents could give several answers): $61.1 \%$ indicated the lack of material and technical base or difficult access to it (in including poor Internet connection) by specialists; $27.4 \%$ lack of methodological assistance on working with visually impaired children of early and preschool age in the online format; $76.4 \%$ lack of direct contact (including tactile) of the child with a specialist; $17.8 \%$ 
psychological barriers they felt due to the need to move to a new format of work; $68.2 \%$ noted the unwillingness of families to do such work; $3.8 \%$ chose the item "Other". Thus, experts consider the biggest obstacles to the lack of direct contact with the child and the unwillingness of families to move to work with ICT. It should be noted that the training, seminars, and the availability of appropriate educational and methodological literature could help overcome these problems and the psychological barriers of the specialists themselves. As for the lack of sufficient material and technical base, it is impossible to solve it within the framework of psychology or pedagogy; this issue should be taken care of by the relevant structures, including and public.

It is interesting to compare the answers described above with the answers to the questions about what was the biggest obstacle and challenge in organizing work using the latest technologies for families of visually impaired children (according to experts): $61.1 \%$ noted the lack of material and technical base or complicated access to it (including poor internet connection) for families; $65.6 \%$ lack of free time for parents (or persons who replace them); $43.9 \%$ of psychological barriers experienced by parents during the transition to the new format; $9.6 \%$ chose the item "Other". Thus, we see that families also had many barriers to implementing the educational process through ICT, some of which can be overcome within the framework of psychology and pedagogy, and some - no.

According to the interviewed experts, families growing up with children with visual impairments need the most help during the lockdown in the following areas (meaning those issues where the support of a teacher or psychologist may be relevant): $78.2 \%$ of assistance in organizing developmental, correctional and training classes; $40.4 \%$ of consultations on the organization of everyday household issues for the care and upbringing of children; $30.8 \%$ assistance in maintaining a favourable microclimate in the family as a whole; $7.7 \%$ of other assistance.

To the question of what the personally interviewed specialist lacks the most in conducting consultations and classes using ICT or increasing their efficiency, the following answers were received: $68.8 \%$ need to improve the material, and technical base (including high-quality Internet communication); $68.8 \%$ lack the desire and willingness of families to work online; $35 \%$ would like to receive scientific and methodological support; $22.3 \%$ feel the need for psychological support from the educational community (supervision, exchange of experiences with colleagues, etc.); $12.7 \%$ overcoming one's psychological barriers and more self-confidence; $6.4 \%$ chose the item "Other".

When asked about the prospects for further development and use of ICT in providing consultations and classes with families of visually impaired children, $75.8 \%$ answered in the affirmative, $24.2 \%$ of respondents do not consider this format promising. In our opinion, this aspect of the study needs to be studied in more detail to determine why experts consider a significant obstacle to the use of ICT in working with families and children and the possibility of overcoming them.

It should also be noted that in response to an open-ended question about what worries professionals in the context of the use of ICT in working with visually impaired children, many of them noted that the issue of preserving children's vision is acute, as well as the lack of conferences (seminars, lectures) including online for parents and professionals who have had to adapt quickly to change.

In parallel with the questionnaire for specialists, a questionnaire was opened for parents (or persons who replace them). One hundred eighty-two people answered this questionnaire. Of these, $97.3 \%$ raise a child with visual impairments, and only $2.7 \%$ are blind. By age, the answers were divided as follows: $0.5 \%$ of the child's parents from birth to 1 year; $7.7 \%$ from one to three years; $24.7 \%$ have a child of the fourth year of life; $33.5 \%$ of the fifth year of life; $33.5 \%$ raise a 5-6-year-old child, $33.5 \%$ 7-8-year-old. Thus, we can see that the activity of parents and their need for training with a specialist increases as the child grows older. 
At the same time, $51.6 \%$ of respondents answered in the affirmative whether a child receives specialized psychological and/or pedagogical assistance in a child care centre, IRC or otherwise, and $48.4 \%$ do not receive such assistance. Thus, we see that the coverage of specialized care for children of early and preschool age with visual impairments is currently insufficient. About half of the children in this category and their families do not receive help from a pedagogue or correctional teacher, a particular psychologist, etc.

Among the surveyed parents, $47.8 \%$ experienced increased anxiety, helplessness, tension during the lockdown. Moreover, 58.2\% noted that the family had additional difficulties in raising and developing the child. Among the difficulties were noted, as problems of material and technical nature and organizational, psychological. Many parents complained about the lack of free time (as mentioned by experts), increased anxiety in children and parents, increased hysteria of children, poor quality of distance learning and the difficulties experienced by children during such activities, lack of live communication more. A special mention should be made of the deterioration of children's well-being associated with the vision strain, including redness and pain in the eyes. All these points indicate that the families of children with visual impairments are in dire need of informational and psychological support in several issues, including the organization of classes and leisure with the use of ICT.

When asked whether, during the hard lockdown in 2020, the family received specialized psychological and/or pedagogical support in a remote format, 52.7\% of respondents answered in the affirmative. Accordingly, $47.3 \%$ did not receive such support.

Among those families who received specialized psychological and/or pedagogical support in a remote format, the most common (respondents were able to choose several items): performing exercises and tasks sent by a specialist $(45.1 \%)$; online classes with children (34.1\%); telephone consultations (25.8\%); online consultations of parents $(22 \%)$; analysis of home video and further consultations on its results $(9.3 \%) ; 3.3 \%$ chose the item "Other".

Among those families who worked with ICT professionals, $43.5 \%$ considered this format effective for their child, $43.5 \%$ could not decide on the issue, and only $13 \%$ believed it was inadequate for their child. We see that a significant proportion of parents and children have specific difficulties and obstacles that hinder the full implementation of the academic press through ICT. The issue of overcoming them needs further study.

Among the respondents, $51.1 \%$ said that in 2021 the situation with receiving specialized psychological and/or pedagogical support in a remote format during a hard lockdown has changed for the better; respectively, $48.9 \%$ did not notice such changes. Note that these figures do not differ significantly from the answers of experts to the same question.

When asked whether parents would like to receive specialized psychological and/or pedagogical assistance in remote and/or face-to-face formats using ICT in the future, $56.6 \%$ answered in the affirmative, $31.1 \%$ have not yet decided, $12.1 \%$ have not would like this. Thus, most parents see the prospects for their children to use ICT in an educational format, but the share of those who have doubts and fears is also relatively high.

According to the respondents, most families with visually impaired children need help in the following areas during the lockdown (meaning the issues where the support of a teacher or psychologist may be relevant): $77.5 \%$ of assistance in organizing developmental classes; $22.5 \%$ of consultations on the organization of everyday life, care and upbringing of children; $18.1 \%$ assistance in maintaining a favourable microclimate in the family as a whole; $16.5 \%$ chose the item "other". We see that the vast majority of families with children with visual impairments are in dire need of help on many issues, so the urgency of organizing such care.

We compare these answers with the answers of specialists. Comparing the data of both groups on the need of families to help organize developmental classes (specialists $78.2 \%$, 
parents $77.5 \%$ ), we see that there is no significant difference between the two groups in this issue $\left(\varphi^{*}=0.046\right)$.

Instead, regarding the need of families for consultations in the organization of everyday life issues, care and upbringing of children (specialists $40.4 \%$, parents $22.5 \%$ ) and the need to help maintain a favourable microclimate in the family as a whole (specialists $30.8 \%$, parents $18,1 \%)$, the opinions of specialists and parents on this issue differ $\left(\varphi^{*}=3.516\right.$ and $\varphi^{*}=2.69$, respectively). The proportion of professionals who believe that families need help in both matters is greater than that of parents who think the same. This can be due to several reasons; for example, specialists do not know and understand the daily life of families with children with visual impairments; family members consider their daily life and family microclimate normal, acceptable, and the expert has a different opinion on this, believes that daily rituals and affairs, family communication needs to change for the better, and so on. It is also possible that there is no close and open contact between families and specialists. There are no honest discussions of failures and successes. This issue needs a separate study.

According to the interviewed parents, the biggest obstacle and challenge in organizing the use of ICT for the family were: $65.9 \%$ noted the lack of direct contact (including tactile) of the child with a specialist; $32.4 \%$ lack of material and technical base or difficult access to it (including poor Internet connection); 20.3\% psychological barriers they experienced during the transition to the new format; $17 \%$ unwillingness of specialists to work in a remote format; $13.7 \%$ chose the item "other".

Comparing the answers of both groups regarding the lack of direct contact (including tactile) of the child with the specialist as the biggest obstacle ( $76.4 \%$ of specialists, $65.9 \%$ of parents), we see that the sensitivity of direct contact between the specialist and the child has become a bigger problem. Specialists $\left(\varphi^{*}=2.139\right)$, although a significant proportion of parents noted it. In our opinion, the significance of this obstacle for specialists is determined by the peculiarities of working with children with visual impairments and the age characteristics of early and preschool age. The difference could also be influenced by the fact that the specialists did not directly contact the child while the parents had it.

Difficulties caused by the lack of material and technical base or difficult access to it (including poor Internet connection) for families were noted by $61.1 \%$ of specialists and $32.4 \%$ of parents. We can see that among the first, a significantly higher proportion of those who believe that this has become a severe obstacle for families to study using ICT $\left(\varphi^{*}=\right.$ 5.362). This difference in shares can be explained by the fact that a significant number of families with difficult access to the Internet were unable to participate in this survey.

There are also differences in views on the psychological barriers experienced by parents during the transition to the new format (43.9\% of professionals, $20.3 \%$ of parents). Experts were much more likely to note psychological barriers in families $\left(\varphi^{*}=4.71\right)$. Several reasons can explain this difference: for example, people often tend to evaluate themselves and others differently, even on the same issue. It is also possible that experts focused on working with children and could not accurately assess the condition and readiness of families to work with ICT. It is also permissible to lack complete contact and, accordingly, honest discussion of the problems in both respondents' groups during distance learning. The issue of complete contact requires further research to determine the causes.

Among the surveyed families, the following formats of remote work are considered the most effective for their child: $54.1 \%$ noted online lessons using ICT; $34.3 \%$ video recording with further analysis and consultation with a psychologist (teacher); $22.1 \%$ of telephone consultations; $19.3 \%$ fulfilment of tasks of a psychologist (teacher) without the use of feedback through ICT; $18.2 \%$ of receiving assignments and writing reports via e-mail; $13.3 \%$ chose the item "other".

Among the answers to the open-ended question about what worries parents the most about this topic, it was expected to be mentioned: fears of reduced visual acuity due to the use of 
gadgets, inability to obtain specialized medical procedures prescribed by an ophthalmologist; lack of special training sessions for specialists and parents on the organization of online training.

\section{Conclusions and prospects of further research}

Based on the analysis of recent research and publications, it can be concluded that the relevance of the use of ICT for remote psychological and pedagogical support of families with children with special educational needs is growing due to global changes in the world and in Ukraine. At the same time, such a category of children as children with visual and preschool visual impairments, their families and professionals who work with them is insufficiently studied in this context.

We can also conclude that children with visual impairments of preschool age are not fully covered by specialized psychological and pedagogical assistance. The lack of such care is especially acute for young children.

During the lockdowns in 2020 and 2021, not all families with preschool children received psychological and pedagogical assistance using ICT. It should also be noted that the transition to a remote format of work was somewhat easier for specialists than for parents. However, both groups had several problems and obstacles along the way. These problems were both material and technical, as well as organizational and psychological. Not all identified problems can be overcome within psychology and pedagogy. Some of them need to be decided at the state level to solve them.

Most experts and parents believe that using ICT for remote psychological and pedagogical support of families raising children with visual impairments is promising. Note that parents have more doubts about this issue than professionals.

The creation of a system of assistance to both parents and specialists in organising remote psychological and pedagogical support for children with visual impairments is acutely relevant. It is necessary to develop, test and implement general approaches and individual methods of educational and, in particular, a correctional process using ICT. Particular attention should be paid to reducing the difficulties in this category of children and professionals who work with them, which arise due to the lack of direct (including tactile) contact.

It should be noted that this study shows that further study requires a number of issues, in particular: the issue of establishing interaction between professionals and parents during the remote format of work; identifying and overcoming psychological barriers in the use of ICT in both groups; preservation of vision in children and prevention of its disorders, as well as prevention of general psychological exhaustion in children, parents and professionals during remote work and isolation; research to increase the effectiveness of the use of ICT in working with families raising children with special educational needs, etc.

It should be noted that scientific research on the use of ICT and remote psychological and pedagogical support, in our opinion, is relevant and promising because this format of work will be in demand not only during the lockdown but also in seasonal outbreaks, challenging weather conditions, as well as permanently for families living in settlements remote from the Irish and other educational institutions. Due to various lifestyles circumstances, these families do not allow to visit institutions that provide educational and psychological services.

\section{References}


1. O.O. Babiak, L.I. Prokhorenko, N.I. Batasheva, Visnyk natsionalnoi akademii pedahohichnykh nauk Ukrainy, 1(2) (2020), https://doi.org/10.37472/2707-305X2020-2-1-7-5 (in Ukrainian)

2. V.Yu. Bykov, S.H. Lytvynova, and O. M. Melnyk, Informatsiini tekhnolohii i zasoby navchannia, $\quad \mathbf{6 ( 6 2 ) ,} \quad 34-46 \quad$ (2017), https://journal.iitta.gov.ua/index.php/itlt/article/view/1937/1289 (in Ukrainian)

3. Brandon Hall's research data. http://www.slideshare.net/msquareg/cms-lms-lcms

4. V.V. Zasenko, Use of information technologies in the conditions of special and inclusive education of children with hearing and speech disorders, http:rc-vaboc.at/ ua/_ld $/ 0 / 9$ .pdf (in Ukrainian)

5. Ye.A. Klopota, Aktualni problemy navchannia ta vykhovannia liudei z osoblyvymy potrebamy, 12(14), 142-155 (2015) (in Ukrainian)

6. V.V. Kobylchenko, Pedahohika i psykholohiia, 2, 64-70 (2016) (in Ukrainian)

7. T.M. Kostenko, V.I. Hoshovskyi, Osvita osib z osoblyvymy potrebamy: shliakhy rozbudovy, 14, 91-95 (2019) (in Ukrainian)

8. L.I. Prokhorenko, O.V. Romanenko, Informatsiini tekhnolohii i zasoby navchannia, 74(6), 266-277 (2019) https://www.researchgate.net/publication/338334638_OSOBLIVOSTI_KLASIFI KACII_OB\%27EKTIV_INFORMACIJNOGO_POLA_DITMI_IZ_ZĀTRIMKO U_PSIHICNOGO_ROZ̄VITKU (in Ukrainian)

9. R. Simpson, Behavior Modification and Child Management, in Handbook on Parent Education, N.Y., USA, 153-158 (1980)

10. A. Talley-Organ, Typical and atypical development in early childhood the fundamentals, Allen Unions, USA (1998)

11. G. Tudg, Collaboration, conflict and cognitive development: the efficacy of joint problem solving, in Proceedings of the Eastern Psychological Conference, 18 April, N.Y., USA (1986) 